\section{A comparative study between ultrasound guided and landmarks guided intraarticular sacroiliac injections in spondyloarthritis patients}

\author{
Plamen Todorov ${ }^{1,2 *}$ and Anastas Batalov ${ }^{1,2}$ \\ 'Department of Propaedeutic of Internal Diseases, Medical University of Plovdiv, Bulgaria \\ ${ }^{2}$ Rheumatology Clinic, UMHAT Kaspela University Hospital, Plovdiv, Bulgaria
}

\section{Abstract}

Purpose: Sacroiliac joints (SIJ) inflammation and pain is particularly common in patients with Spondyloarthritis. Intraarticular SIJs injections represent a valuable therapeutic option in this condition. In the rheumatological outpatient clinics this procedure is usually done by landmark guidance (LG) or ultrasound guidance (USG).

Thus we aimed to compare the short term efficacy of USG vs. LG SIJ injections using five outcome measures: 1. Pain; 2 . SIJ status (number of positive provocation tests per symptomatic SIJ on physical examination); 3. Disability; 4. Quality of the night sleep; 5. Patients' satisfaction.

Methods: We enrolled 44 consecutive spondyloarthritis patients with pain in the SIJs that did not respond to NSAIDS and that were otherwise on a stable medical treatment. All patients also $\mathrm{had} \geq 3$ positive pain provocation tests per SIJ on physical examination. Patients were randomly allocated to receive a single SIJ injection with $7 \mathrm{mg}$ Betamethasone $(1 \mathrm{ml})$ and $1 \%$ Lidocaine $(1.5$ $\mathrm{ml}$ ) either under USG or with LG.

Results: Both groups showed significant improvement in all outcome parameters. However, the USG approach performed significantly better than the LG ones in all parameters. In addition, there was a significant correlation between the improvement in all patient reported outcomes (VAS, RMDQ, JSEQ) and the reduction in the number of positive SIJ pain provocation tests per symptomatic joint.

Conclusion: Both USG and LG SIJ injections proved to be an efficient treatment for SIJ pain in SpA patients. However, USG of the intervention led to statistically better results in the present study.

\section{More Information}

*Address for Correspondence: Plamen Todorov, Kaspela University Hospital, bl 2, fl 7, 64, Sofia Str Plovdiv 4002, Bulgaria, Tel: +00359 888566478; Email: drtodorovplamen@gmail.com

Submitted: 05 March 2020

Approved: 16 March 2020

Published: 17 March 2020

How to cite this article: Todorov $P$, Batalov $A$. A comparative study between ultrasound guided and landmarks guided intraarticular sacroiliac injections in spondyloarthritis patients. Arch Clin Exp Orthop. 2020; 4: 001-008.

DOI: 10.29328/journal.aceo.1001007

ORCiD: orcid.org/0000-0002-9887-6064

Copyright: (c) 2020 Todorov P, et al. This is an open access article distributed under the Creative Commons Attribution License, which permits unrestricted use, distribution, and reproduction in any medium, provided the original work is properly cited

Keywords: Sacroiliac joints, Spondyloarthritis, Injections, Ultrasound-guided, Landmark-guided

Check for updates

OPEN ACCESS

\section{Introduction}

Inflammation of the sacroiliac joints (SIJ) is the hallmark of Spondyloarthritis (SpA) [1]. Sacroiliitis and the inflammatory low back pain (IBP), lead not only to worsening of the patients' functional capacity and work performance, butalso to a notably poor quality of night sleep and rest [2]. Despite the active systemic treatment with nonsteroidal anti-inflammatory drugs (NSAIDS), disease-modifying anti-rheumatic drugs (DMARD) and/or biologic agents, that patients receive, many of them still have profound and disabling sacroiliac pain [3]. In this case, the application of potent anti-inflammatory drugs like corticosteroids directly into the SIJs, seems a good therapeutic option to alleviate patient's complaints [4].

SIJ intraarticular injections could be performed by several approaches regarding the center and/or the physician' expertise. Traditionally, like other musculoskeletal (MSK0 interventions, SIJ injections were done by landmark guidance (LG) [5]. Anyway, because of the complex anatomy of SIJs, the accuracy of this approach was questioned and some kind of image guidance for the procedure has been preferred [6]. Injections under fluoroscopic guidance are safe, accurate and commonly performed in multidisciplinary pain centers 
with good effect in about two thirds of the patients [7]. However, they carry substantial risk of ionizing radiation for the patient and for the physician, and moreover they require an additional appointment at another department, as well as there is a potential risk of allergic reaction to the contrast media [8]. The Computer tomography (CT) guided injections are accurate but also require complex settings and equipment and involve radiation exposure [9]. Most of these holds true also for magnetic resonance imaging (MRI) assisted sacroiliac injections. Here there is no risk of radiation, but the cost is high, MRI machines are still not readily available, and in addition, there is an issue with claustrophobia and some implants [10], as well it may induce adverse biological effects [11]. Performance of SIJ injections under ultrasound guidance (USG) is a novel approach, representing the growing popularity of ultrasound (US) not only in rheumatology, but in musculoskeletal medicine in general. USG SIJ injections are relatively fast and cheap, as well as accurate after adequate training $[12,13]$.

There is sufficient data that USG increases substantially the success rate for intraarticular or periarticular injections for many joints and soft tissue structures [14]. However, for some of the human joints, including the SIJs, such data is lacking. This study aims to fill to some extent this gap comparing the short term (8 weeks) efficacity of USG vs. LG SIJ injections on: 1. Self-reported SIJ pain on visual-analogue scale (VAS), 2. SIJ status (number of positive sacroiliac provocation tests per symptomatic SIJ), 3. Disability due to pain (Roland Morris Disability Questionnaire - RMDQ), 4. Quality of the night sleep (Jenkins Sleep Evaluation Questionnaire - JSEQ), as well as the patients overall satisfaction from both procedures ( 3 point Likert scale).

\section{Methods}

We enrolled 44 consecutive SpA patients with pain in the sacroiliac region that did not respond to NSAIDS and that were otherwise on stable medical treatment. Inclusion criteria were age above 18, diagnosis of SpA and satisfying Assessment in Spondyloarthritis International Society (ASAS) criteria, pain in one or both SIJs that interfere with their everyday activities; at least three (out of six) positive SIJ provocation tests per joint (see below). Exclusion criteria: oral corticosteroid treatment or local corticosteroid injection in the previous three months, infection, uncontrolled diabetes or hypertension. All subjects signed an informed consent form and the study was approved by the hospital ethical committee.

Each patient underwent comprehensive examination of the painful sacroiliac joints that include the performance of six sacroiliac pain provocation tests [15]: 1. Iliac gapping (with the patient positioned supine, the examiner crossed his arms, placed the palms of his hands on the anterosuperior iliac spines and pressed downward and laterally); 2. Iliac compression (with the patient lying on his side, the examiner exerted downward force on the uppermost iliac crest); 3. Midline sacral thrust test (the examiner applies a posteroanterior force to the sacrum as the patient lies prone); 4. Gaenslen's test (the patient lies supine as the contralateral hip is flexed and the ipsilateral hip is extended); 5. Patrick's test (stress of the SIJ by flexion, abduction and external rotation of the hip). 6. Sulcus test: pain on palpation in the sulcus between the posterior superior iliac spine and the sacrum. The results of these tests were considered positive if pain was provoked1 at the SIJ in left or right. According to different authors, none of these SIJ provocation tests appears to be superior to the others and the reliability of any single one of them, performed in isolation, is questionable [16]. Therefore, in practice, the clinical diagnosis of sacroiliitis requires several of these tests (usually three) to be simultaneously positive in the given joint $[17,18]$. Thus, the clinical status of SIJs in our study was defined by the cumulative number of positive sacroiliac pain provocation tests per joint.

The level of SIJ pain was quantified by patients on $0-10$ VAS. In addition, the functional disability and sleep disturbances caused by the SIJ pain were self-assessed by all patients, completing the Roland-Morris Disability Questionnaire (RMDQ) and Jenkins Sleep Evaluation Questionnaires (JSEQ), respectively.

Then patients were randomized via a computer program (Research Randomizer ${ }^{\circledR}$ - one set of numbers, number range 1-2) in two parallel groups with a 1:1 ratio. According to the group allocation, patients were given an injection with $7 \mathrm{mg}$ Betamethasone $(1 \mathrm{ml})$ and $1 \%$ Lidocaine $(1.5 \mathrm{ml})$ into the painful SIJ under USG or with LG.

\section{Methodology of the procedure}

1. LG SIJ injections: We followed the approach described by Saunders and Longworth [5] enriched by the data provided from Zou, et al. detailed anatomical and radiological study on SIJ injection [19]: The patient was lying prone over a small pillow and the posterior superior iliac spine (PSIS) on the affected side was identified. A 22G, $9 \mathrm{~mm}$ spinal needle (Spinocan) was inserted in a point that was at a thumb's width inferior to PSIS and at the same time $3.5 \mathrm{~cm}$ lateral from the midline (approximately at the level of the second sacral spinous process), as shown on figure 1 . The needle was then angled obliquely in posterior and slightly cranial direction and advanced. If it came up against bone it was maneuvered around until a ligamentous resistance was felt and the solution was then slowly injected.

2. USG injection: Esaote My Lab 7 machine with $5 \mathrm{~cm}$ footprint linear probe 4-12 $\mathrm{MHz}$ was used. Low frequency mode was applied. The patient was lying in prone position over a small pillow and a strict scanning protocol was followed. First, the probe was placed in the transverse plane in the midline over the sacrum. After the characteristic contour of the sacral spinous processes was identified, the probe was moved first up until L5-S1 space was reached. Then the 
probe was slid laterally over the sacral wing to the side of the painful joint until the bony contour of the PSIS was identified. Then the probe, still in the transverse plane was moved down following the cleft between the iliac bone and the sacrum, which represents the homolateral SIJ. The sacral foramina (seen as a break in the hyperechoic contour of the sacral wing) were counted and the probe was finally placed just cranial to the second one. Here the lateral part of the probe was rotated counterclockwise with several degrees to a slightly oblique position, so that the posterior sacroiliac ligament (PSL) was visualized sufficiently well in its long axis -the typical SIJ image in this position is shown in figure 2 .

Then a 22G, $9 \mathrm{~mm}$ spinal needle (Spinocan) was inserted at the medial side of the probe following an in-plane free-hand technique, as seen in figure 3 . When the needle tip was seen to penetrate the PSL and enter the SIJ, $0.2 \mathrm{ml}$ of the solution was injected to confirm that it spreads beneath the PSL, rather than above or in this ligament. After that, a Color Doppler (CD) box was activated and placed over the SIJ to monitor the spread of the injected solution and ensure that it keeps bellow the PSL all through the procedure, as shown in figure 4. The whole solution was injected under this direct US and $\mathrm{CD}$ visualization and the needle tip was repositioned beneath the PSL if needed. All procedures were performed by one physician (PT) with more than 12 years of experience with MSK interventions and more than 7 years with MSK US, at the time of the study.

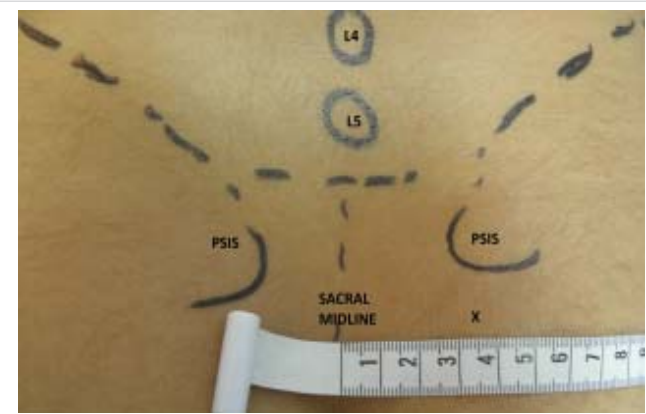

Figure 1: Positioning for a landmark-guided sacroiliac joint injection, the needle entry site is marked with X (PSIS - Posterior Superior lliac Spine; L4, L5 - tips of the spinous processes of the respective vertebra).

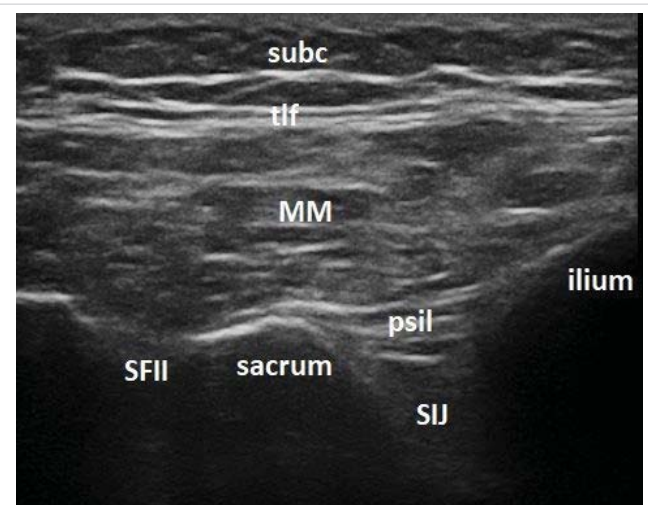

Figure 2: Ultrasound image of the sacroiliac joint with the transducer positioned as in figure 2 (SIJ - sacroiliac joint; SFII - second sacral foramen; psil - posterior sacroiliac ligament; MM -multifidus muscle; tIf -thoracolumbar fascia; subc subcutaneous tissue).

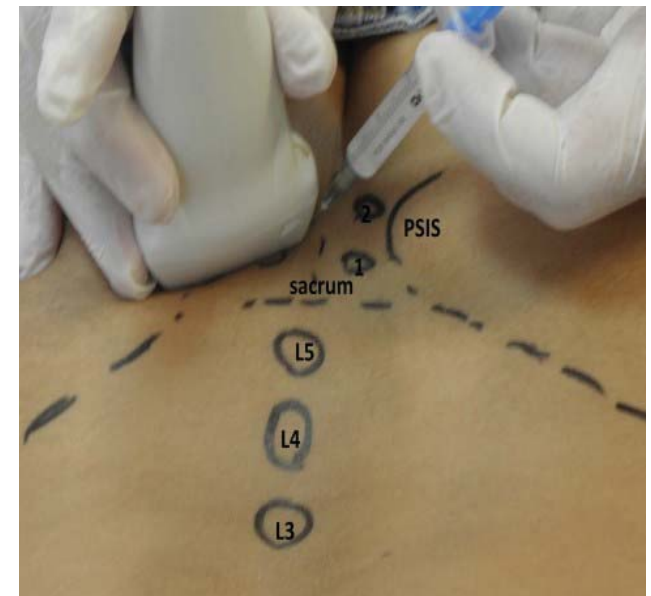

Figure 3: Positioning for an ultrasound-guided sacroiliac joint injection, the probe is orientated in a slightly oblique manner (PSIS - Posterior Superior lliac Spine; L4, L5 - tips of the spinous processes of the respective vertebra, 1,2 - corresponding sacral foramina)

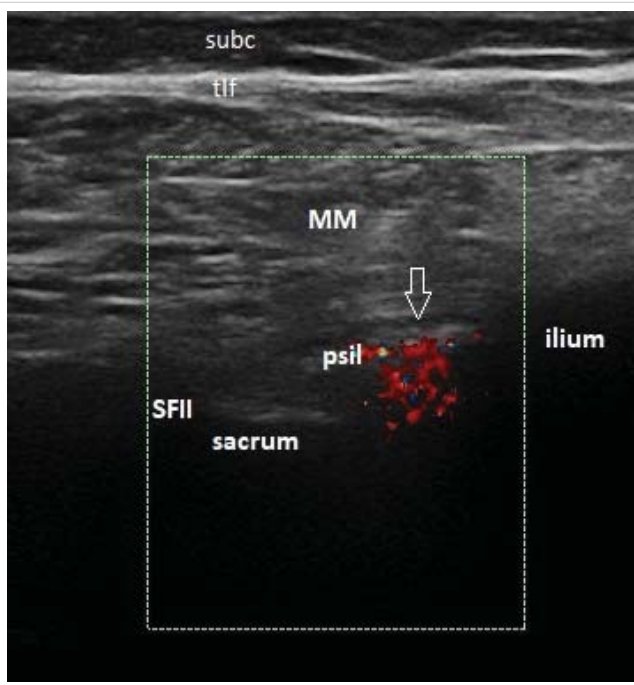

Figure 4: Ultrasound-guided sacroiliac joint injection; the color Doppler box shows that the solution's flow is under the posterior sacroiliac ligament - arrow (SFI second sacral foramen; psil - posterior sacroiliac ligament; MM -multifidus muscle; tlf -thoracolumbar fascia; subc - subcutaneous tissue).

All patients stayed under observation for an hour after the procedure for possible adverse reactions and/or anesthetic leakage to nerve structures.

The patients were followed up and examined after an average period of 8 weeks for the therapeutic effect of the procedure. At this visit the patients completed VAS, RMDQ and JSEQ forms. The status of the injected SIJ was assessed again by the previously described six SIJ pain provocation tests. In addition, at this visit all patients pointed whether they were satisfied by the procedure on a three-point Likert scale (Yes, No, Neither of these).

\section{Statistical analysis}

The data was analyzed using the Statistical Package for the Social Sciences (SPSS), Version 25. Descriptive statistics for continuously measured and normally distributed variables (if Kolmogorov-Smirnov test, $p>0.05$ ) include mean values \pm 
standard deviation (SD) and frequencies and percentages for nominal and ordinal variables. The two treatment groups (USG vs. LG injection) were compared on continuously measured demographic and clinical data through independent samples t-tests. The internal dynamics within each treatment group was examined through paired-samples t-tests. Between-group comparisons on nominal and ordinal data were performed through crosstabulation, the chi-square test and Fisher's exact test. Results were interpreted as statistically significant at Type I error alpha $\leq 0.5$.

\section{Results}

The sample involved 44 patients with SpA, 24 males and 20 females of mean age $44.16 \pm 13.25$ that were randomly assigned to two treatment groups. The baseline demographic characteristics of all the patients, as well as the two study groups are presented in table 1 . The groups did not differ significantly in neither the general demographic, disease related or treatment related characteristics, nor the four study outcome parameters at baseline, as seen in table 1 and table 2 . The patients in both groups were allocated in two parallel groups and underwent an intraarticular SIJ injections by a LG or USG approach.

Two months after the injection, both patients' groups showed a statistically significant decrease in values on all four outcome parameters, i.e. symptomatic improvement. We then compared the effectiveness of both approaches in SIJ related pain in SpA patients using the same outcome measures. Two months after the injection, the USG intervention group showed significantly higher rates of improvement on all four parameters compared to the LG group (Table 3). The mean number of positive SIJ pain provocation tests per joint dropped by $70 \%$ vs. $50 \%$ in the LG injection group, $p=0.044$. The VAS mean score decreased by $68 \%$ in USG vs. $30.5 \%$ in the LG group, $p=0.004$. In addition, there was a reduction by $46 \%$ in the RMDQ in USG vs. $12 \%$ in the LG injection group ( $p$ $=0.031$ ); and a decrease by $41 \%$ in the JSEQ score $v s .22 \%$ in the LG group ( $p=0.036)$.

\begin{tabular}{|c|c|c|c|c|c|}
\hline \multicolumn{2}{|c|}{ Variables } & $\begin{array}{c}\text { Total } \\
(N=44)\end{array}$ & \multicolumn{3}{|c|}{$\begin{array}{l}\text { GROUP } \\
\text { US-guided Landmark-guided } p(N=22)(N=22)\end{array}$} \\
\hline \multicolumn{2}{|c|}{$\begin{array}{c}\text { Age } \\
\text { Mean } \pm \text { SD }\end{array}$} & $44.16 \pm 13.25$ & $43.14 \pm 12.07$ & $45.18 \pm 14.54$ & 0.614 \\
\hline \multirow{2}{*}{ Gender $N(\%)$} & Male & $24(54.5 \%)$ & $11(50 \%)$ & $13(59 \%)$ & \multirow{2}{*}{0.545} \\
\hline & Female & $20(45.5 \%)$ & $11(50 \%)$ & $9(41 \%)$ & \\
\hline \multicolumn{2}{|c|}{$\begin{array}{l}\text { Disease duration (years) } \\
\text { Mean } \pm \text { SD }\end{array}$} & $6.21 \pm 4.58$ & $5.29 \pm 4.04$ & $7.13 \pm 5.12$ & 0.194 \\
\hline \multirow{3}{*}{$\begin{array}{c}\text { Type } \\
\text { Spondylitis N (\%) }\end{array}$} & AS & $17(38.6 \%)$ & $8(36.4 \%)$ & $9(40.9 \%)$ & \multirow{3}{*}{0.939} \\
\hline & PsA & $12(27.3 \%)$ & $6(27.3 \%)$ & $6(27.3 \%)$ & \\
\hline & $\mathrm{SpA}$ & $15(34.1 \%)$ & $8(36.4 \%)$ & $7(31.8 \%)$ & \\
\hline \multirow{4}{*}{$\begin{array}{l}\text { Medication } \\
\text { Used (\%) }\end{array}$} & NSAID & $25(56.8 \%)$ & $11(50 \%)$ & $14(63.3 \%)$ & \multirow{4}{*}{0.768} \\
\hline & TNFa inh & $9(20.5 \%)$ & $5(22.7 \%)$ & $4(18.2 \%)$ & \\
\hline & Methotrexate & $6(13.6 \%)$ & $4(18.2 \%)$ & $2(9.1 \%)$ & \\
\hline & Salazopyrine & $4(9.1 \%)$ & $2(9.1 \%$ & $2(9.1 \%)$ & \\
\hline \multicolumn{2}{|c|}{$\begin{array}{l}\text { CRP }(\mathrm{mg} / \mathrm{l}) \\
\text { Mean } \pm \mathrm{SD}\end{array}$} & $5.59 \pm 4.09$ & $5.50 \pm 4.03$ & $5.68 \pm 4.14$ & 0.883 \\
\hline \multicolumn{2}{|c|}{$\begin{array}{c}\text { BASDAI } \\
\text { Mean } \pm \text { SD }\end{array}$} & $4.46 \pm 0.66$ & $4.34 \pm 0.67$ & $4.58 \pm 0.65$ & 0.237 \\
\hline
\end{tabular}

AS: Ankylosing Spondylitis; PsA: Psoriatic Arthritis; SpA: undifferentiated Spondyloarthris; NSAID: Non-Steroidal Anti-Inflammatory Drugs; TNFa inh: Tumor Necrosing Factor a inhibitors; CRP: Creactive Protein; BASDAl: Bath Ankylosing Spondylitis Disease Activity Index; SD: Standard Deviation; US: Ultrasound.

Table 2: Pre-injection disease parameters.

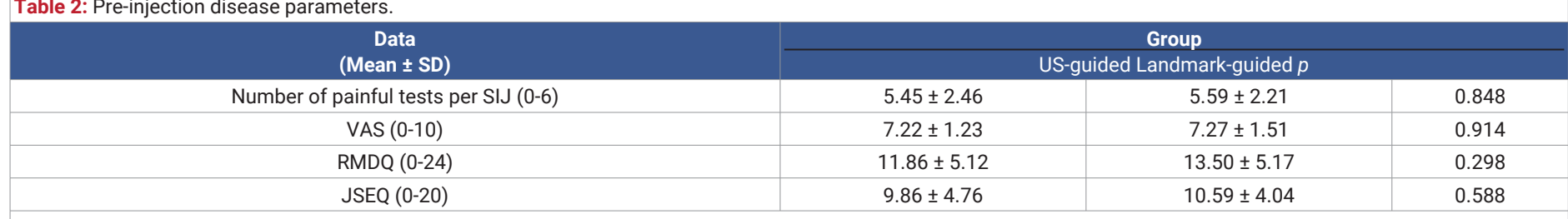

VAS: Visual Analogue Scale; SD: Standard Deviation; RMDQ: Roland-Morris Disability Questionnaire; JSEQ: Jenkins Sleep Examination Questionnaire

Table 3: The effectiveness of the US-guided versus landmark-guided injection method.

\begin{tabular}{|c|c|c|c|c|c|}
\hline \multirow{3}{*}{ Parameters } & \multicolumn{4}{|c|}{ Group } & \multirow{3}{*}{ p } \\
\hline & \multicolumn{2}{|c|}{ US-guided } & \multicolumn{2}{|c|}{ Landmark-guided } & \\
\hline & Mean \pm SD & $\%$ decrease & Mean \pm SD & $\%$ decrease & \\
\hline $\mathrm{N}$ of painful tests per SIJ (0-6) & $1.63 \pm 1.94$ & $-70 \%$ & $2.94 \pm 1.86$ & $-50 \%$ & $0.044^{*}$ \\
\hline VAS $(0-10)$ & $2.28 \pm 2.37$ & $-68 \%$ & $5.05 \pm 3.04$ & $-30.5 \%$ & $0.004^{\star *}$ \\
\hline RMDQ (0-24) & $6.42 \pm 6.39$ & $-46 \%$ & $11.33 \pm 6.93$ & $-12 \%$ & $0.031^{*}$ \\
\hline JSEQ (0-20) & $5.84 \pm 3.43$ & $-41 \%$ & $8.22 \pm 3.17$ & $-22 \%$ & $0.036^{*}$ \\
\hline
\end{tabular}

SIJ: Sacroiliac Joint; SD: Standard Deviation; VAS: Visual Analogue Scale; RMDQ: The Roland-Morris Disability Questionnaire; JSEQ: Jenkins Sleep Examination Questionnaire 
The higher improvement rates in the USG injection group are further collaborated by the patients' level of satisfaction. The majority of the USG injection patients (63\%) were satisfied with the treatment, while the majority of patients (55\%) in the LG injection group answered neither yes nor no, and only $28 \%$ were satisfied with the treatment ( $p=0.033)$.

In addition, we also calculated the percentage of patients who have achieved improvement of $\geq 50 \%$ on the patient reported outcome parameters for both groups and in total. The results showed the highest rate of improvement on the VAS scale, where $68 \%$ of the patients in the USG group reached $\geq 50 \%$ improvement in their symptoms vs. $51 \%$ of the patients in the LG group, and $59.5 \%$ in total. This was followed by the RMDQ, where $63 \%$ of the patients in USG group reported $\geq$ $50 \%$ improvement and $30 \%$ of those in the LG group, resulting in a total of $48 \%$ for all patients. The lowest improvement rate of $\geq 50 \%$ was observed on the JSEQ with $36 \%$ in the USG group and $22 \%$ in the LG, thus $29 \%$ in total. This data is summarized in table 4.

Interestingly, we obtained significant correlations between the percentage of improved symptoms, based on the patient reported outcome parameters (VAS, RMDQ and JSEQ), and the improvement in the SIJs' status, i.e. the reduction in the number of positive SIJ pain provocation tests per a symptomatic joint

\begin{tabular}{|c|c|c|c|}
\hline \multicolumn{2}{|c|}{ Table 4: Percentage of patients with $\geq 50 \%$ improvement on the outcome measures. } \\
\hline Group & VAS & RMDQ & JSEQ \\
\hline US-guided & $68 \%$ & $63 \%$ & $36 \%$ \\
\hline Landmark-guided & $51 \%$ & $30 \%$ & $22 \%$ \\
\hline Total & $59.5 \%$ & $48 \%$ & $29 \%$ \\
\hline
\end{tabular}

VAS: Visual Analogue Scale; RMDQ: The Roland-Morris Disability Questionnaire; JSEQ: Jenkins Sleep Examination Questionnaire on physical examination. These correlations were as follows: for VAS: $r=0.846, p=0.001$; or RMDQ: $r=0.766, p=0.006$; for JSEQ: $r=0.592, p=0.049$. Higher percentage of patient reported improvement was associated with a higher reduction in the number of positive tests per a symptomatic SIJ on the clinical examination (Figure 5).

No adverse reactions (except some periprocedural pain) were noted in both groups.

\section{Discussion}

In the present study, we compare the effectiveness of intraarticular SIJ injections performed under US guidance, with those performed under LG. LG (or the so called "blind") SIJ injections are traditionally considered unreliable [20]. However, the results in the literature are not univocal. In their study Rosenborg, et al. showed that only $22 \%$ of the LG injections reached the cavity of the SIJ [21], and the results were even worse in the study performed by Hansen, where only five out of the sixty patients received proper intraarticular injections [22]. On the contrary, Sedreddini, et al. reported pain improvement in 59\% of the patients with various types of Spondyloarthritis after unguided sacroiliac injections [23]. Their study lasted for 20 weeks and showed in addition to pain reduction, an improvement in sleep disturbances and morning stiffness, as well as a decrease in MRI inflammatory scores. Besides, Zou, et al. reported that 13 out of 20 unguided SIJ injections performed in their study reached the joint cavity (confirmed by radiographic contrast media) constituting a success rate of 65\% [19]. Moreover, 11 of these 13 injections reached the intraarticular space at the first attempt.

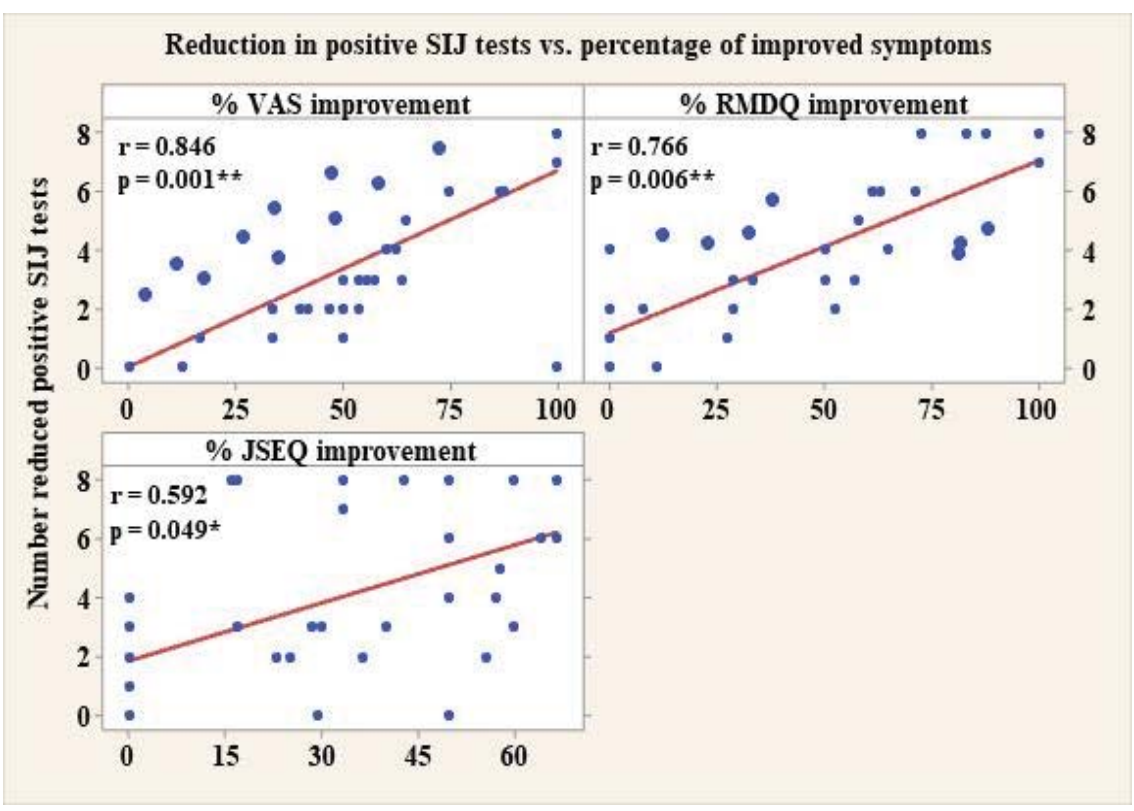

Figure 5: Correlation between the numerical reduction in positive SIJ pain provocation tests and patients' symptomatic improvement. (SIJ: Sacroiliac Joint; Cl: Confidence Interval; VAS: Visual Analogue Scale; RMDQ: Roland-Morris Disability Questionnaire; JSEQ: Jenkins Sleep Examination Questionnaire). 
The accuracy of USG interventions was also evaluated in several studies. Klauser, et al. reported a success rate of intraarticular access of $80 \%$ in a cadaver study of US guided SIJ injections and the efficacy was the same in the 10 patients injected in the clinical part of the study [24]. These results were confirmed also by Perry, et al. who reported $88 \%$ accuracy of the US guided approach [13]. Jee, et al. compared the accuracy and the therapeutic efficacy of SIJ injections performed with USG and with fluoroscopic guidance in 120 patients with noninflammatory pain. While the accuracy of delivering intraarticular injections was higher in the fluoroscopic group (98.2 vs. 87.3\%), the therapeutic effect (evaluated based on both pain and function improvement) was not statistically significant between groups. In addition, the learning curve for USG SIJ injections seems to be relatively steep, with a success rate of correct needle placement reaching $93.5 \%$ after only 30 procedures [25].

In our study, we have used the in plain method for USG, because of two main reasons. First, it allows the visualization of the sacral foramina, so they could be avoided. Second, this approach allows the visualization of the PSL in its long axis, thus the tip of the needle could be monitored and kept under this structure throughout the procedure, assuring intraarticular injection (as the PSL constitutes the posterior capsule of the SIJ) [26].

Interestingly, in several studies on SIJ injections, there was not a relation between the correct intraarticular drug administration and the therapeutic efficacy. Thus, Nacey, et al. performed a retrospective analysis of 99 patients $(55$ with intraarticular, 58 with periarticular fluoroscopy guided SIJ injections) and found no difference in pain alleviation between both groups [27]. Furthermore, two other studies, a prospective one, done by Murakami, et al. [28], and a retrospective one, performed by Borowsky and Fagen [29], showed better results with periarticular compared to intraarticular SIJ fluoroscopy guided injections. Explanations for this phenomenon include the histological observations of pain sensitive tissue in the posterior ligamentous tissue, the sacral nerve rami, which perforate the posterior sacroiliac ligament, the possible entheses origin of pain, and the unique anatomy of the SIJ with a comparatively small for their size synovial compartment $[26,30]$.

It must be pointed out, however, that the above-mentioned studies have included patients with mechanical, rather than inflammatory origin of the pain. In this type of pain, the supporting structures of the joint (ligaments, capsule, entheses), as well as surrounding nerve structures or referred pain could be responsible for much of the complaints. For example, calcitonin gene-related peptide and substance $P$ immunoreactive nerve fibers where proven histologically in the sacroiliac interosseous ligaments as well as in the PSL [30]. On the contrary, our study included only patients with inflammatory disease - SpA, that were on systemic treatment (most with NSAIDS) which could already influence these other sources of pain. In addition, the blind injections in the present study were performed following a protocol and an approach similar for all participants, while the US guided procedures could have individual variations in performance, according to the sonoanatomy and the acoustic windows of the individual patient. As bony changes, enthesopathy and joint space narrowing of the SIJ occurs in all patients with SpA, blind injections could end up not only extraarticular, but also away from the other potentially pain generating structures around the SIJ (ligaments and tendons entheses). On the contrary, our approach with US visualization of the needle tip under the PSL, as well as, maintaining it there through the entire procedure guarantied medication delivery in close proximity to all of the important pain generating structures - synovial space, interosseous ligaments, PSL, their entheses, the sacral rami and the joint capsule. In addition, the study of Fortin, et al. shows that in more than $60 \%$ of cases with fluoroscopic guided SIJ injections, there is a leakage of the intraarticularly injected solution from the SIJ to the surrounding (mostly posterior, due to capsular defects) structures [31]. Thus, the intraarticularly injected medication may have broader than originally presumed spread and thus also an effect on the periarticular structures.

Traditionally the SIJ intraarticular procedures target the most caudal part of the joint $[2,7,24,25]$. This anterior-inferior part is lined with synovium, i.e., constitute the true joint cavity, contrary to the larger posterior-superior part of the joint, which is ligamentous [26]. However, most of the studies in SpA show that the primary structures to be affected in this group of diseases are the entheses [32], thus the upper part of the joints could be more important as pain generator given the numerous ligamentous entheses that it consists of. In our approach (both USG and LG) the needle was directed also to several degrees cranially, and not only posteriorly. This was done for two reasons: first in this way, the corticosteroid solution reached also the entheses of the intraosseous ligaments; and second - with the USG injections, this scanning plane makes the PSL well detectable and it is easier to have a visual control and to keep the tip of the needle under it during the entire procedure.

In our study, more than $50 \%$ improvement of pain on the VAS was reached in $68 \%$ of the patients in the USG group and $51 \%$ of the patients in the LG group; thus, in a total of $59.5 \%$ of all patients included. This is in line with previous studies on the efficacy of the SIJ injections, performed with various guidance. Similar, Jee, et al. reported good effect (no additional treatment required) in $69.8 \%$ of the AS patients, which underwent fluoroscopy guided SIJ injections [25]. Sadreddini et al reported $\geq 50 \%$ improvement of pain in 59\% of their SpA patients after LG SIJ injections [23]. Braun, et al. reported significant improvement of IBP in $83.3 \%$ of their patients after CT guided SIJ injections [33] while Frits, et al. found out an improvement in pain by more than 50\% in $85 \%$ of their AS patients with MRI guided injections [10]. 
Considering noninflammatory SIJ pain, the results are mixed: for example, Kim et al reported very good therapeutic result in $70 \%$ of patients [34], while on the contrary Borowsky and Fagen found effect in only $12.5 \%$ of the patients [29] and Slipman in $25 \%$ of patients who received fluoroscopy guided injections for mechanical SIJ pain [35]. In addition, Savran, et al. found that CT guided intraarticular injections are counterproductive in the long term in high grade osteoarthritis of the SIJ [36].

Traditionally SIJ pain provocation tests are regarded unreliable in the diagnosis of SIJ pathology, as many structures overlap in the region $[15,16]$. On the contrary, our results show a clear correlation between the patients' reported level of pain and the number of the positive SIJ provocation tests. We observed a significant reduction in the number of positive tests eight weeks after injections that were in line with the pain intensity reduction on VAS. These results correspond to those of Murakami, et al. reported previously [27]. On the other hand, the number of positive provocation tests per joint remained high for the patients that did not have an effect from the intervention, regardless of the injection guidance. Thus, our results show that, first the pain provocation tests could assess the true status of the SIJ (unless in sacroiliitis), and second, as an outcome measure, they are sensitive to change with treatment, and accordingly they could be used in future clinical trials on treatment options in SIJ pathology.

This study has also certain limitations. Firstly, the long-term effects of these injections were not evaluated, but for logistic reasons the follow up was limited to 8 weeks. In addition, with the new approach of tailored treatment strategy, it would be unethical to keep all components of the patients' therapy fixed for a longer period, in order to follow the effect of a single procedure. Secondly, most of the injections were performed in patients with a BMI of less than $30 \mathrm{~kg} / \mathrm{m} 2$. The degree of difficulty in performing the US guided injection could be accentuated by a patient's high body mass index (BMI), Higher BMI would undoubtedly increase the US beam attenuation as well as the depth of the injection site. Needle visualization would decrease because of the steeper angle that is required for a deeper injection and furthermore the needle would be less visible among the hyperechoic fat tissue. Thirdly, the treatment procedures, both LG and USG, were conducted by the same physician. Thus, the reported outcomes may have reflected the experience of this practitioner, which may limit the generalization of the results. Lastly, in the present study parameters that reflect the SpA disease activity like CRP or BASDAI were collected only on baseline and not at the follow up visit. However, we considered that the SIJ injections are a local intraarticular treatment that has no necessary a global effect on the disease itself.

In conclusion, intraarticular SIJ proved to be a reliable treatment option in patients with sacroiliitis. This procedure should be performed under USG, if possible, as this further increase its therapeutic effectivity.

\section{References}

1. Braun J, Sieper J. Ankylosing spondylitis. Lancet. 2007; 369: 1379-90. PubMed: https://www.ncbi.nlm.nih.gov/pubmed/17448825

2. Cohen SP. Sacroiliac joint pain: a comprehensive review of anatomy, diagnosis, and treatment. Anesth Analg. 2005; 101: 1440-1453.

PubMed: https://www.ncbi.nlm.nih.gov/pubmed/16244008

3. Hawkins J, Schofferman J. Serial therapeutic sacroiliac joint injections: a practice audit. Pain Med. 2009; 10: 850-853.

PubMed: https://www.ncbi.nlm.nih.gov/pubmed/19594847

4. Maugars $Y$, Mathis $C$, Vilon $P$, Prost $A$. Corticosteroid injections of the sacroiliac joint in the seronegative spondyloarthropathies. Arthritis Rheum. 1992; 35: 564-568.

5. Saunders S, Longworth S. Injection techniques in Orthopedics and Sport Medicine. A practical manual for doctors and physiotherapists. $3^{\text {rd }}$ Edition, Elsevier. 2006.

6. Rana SH, Farjoodi P, Haloman S, Dutton P, Hariri A, et al. Anatomic Evaluation of the Sacroiliac Joint: A Radiographic Study with Implications for Procedures. Pain Physician. 2015; 18: 583-92.

7. Karabacakoglu A, Karaköse S, Özerbil ÖM, Odev K. Fluoroscopyguided intraarticular corticosteroid injection into the sacroiliac joints inpatients with ankylosing spondylitis. Acta Radiol. 2002; 43: 425-427. PubMed: https://www.ncbi.nlm.nih.gov/pubmed/12225487

8. Dussault RG, Kaplan PA, Anderson MW. Fluoroscopy-guided sacroiliac joint injections. Radiology. 2000; 214: 273-277.

PubMed: https://www.ncbi.nlm.nih.gov/pubmed/10644136

9. Block BM, Hobelmann JG, Murphy KJ, Grabow TS. An imaging review of sacroiliac joint injection under computed tomography guidance. Reg Anesth Pain Med. 2005; 30: 295-298.

PubMed: https://www.ncbi.nlm.nih.gov/pubmed/15898034

10. Fritz J, Henes JC, Thomas C, Clasen S, Fenchel M, et al. Diagnostic and interventional MRI of the sacroiliac joints using a 1.5-T open-bore magnet: a one-stop-shopping approach. AJR Am J Roentgenol. 2008; 191: 1717-1724.

PubMed: https://www.ncbi.nlm.nih.gov/pubmed/19020241

11. Fedorowski A, Steciwko A. Biological effects of non-ionizing electromagnetic radiation. Med Pr. 1998; 49: 93-105.

PubMed: https://www.ncbi.nlm.nih.gov/pubmed/9587915

12. Pekkafahli MZ, Kiralp MZ, Başekim CC, Silit E, Mutlu H, et al. Sacroiliac joint injections performed with sonographic guidance. J Ultrasound Med. 2003; 22: 553-559.

PubMed: https://www.ncbi.nlm.nih.gov/pubmed/12795552

13. Perry JM, Colberg RE, Dault SL, Beason DP, Tresgallo RA 3rd. A Cadaveric Study Assessing the Accuracy of Ultrasound-Guided Sacroiliac Joint Injections. PM R. 2016; 8: 1168-1172.

PubMed: https://www.ncbi.nlm.nih.gov/pubmed/27178376

14. Kane D, Koski J. Musculoskeletal interventional procedures: With or without imaging guidance? Best Pract Res Clin Rheumatol. 2016; 30: 736-750.

PubMed: https://www.ncbi.nlm.nih.gov/pubmed/27931965

15. Bogduk N. Pain provocation tests for the assessment of sacroiliac joint dysfunction. J Spinal Disord. 1999; 12: 357-358.

PubMed: https://www.ncbi.nlm.nih.gov/pubmed/10451054

16. Cattley $P$, Winyard J, Trevaskis J, Eaton S. Validity and reliability of clinical tests for the sacroiliac joint: a review of literature. Australas Chiropr Osteopathy. 2002; 10: 73-80.

PubMed: https://www.ncbi.nlm.nih.gov/pubmed/17987177

17. van der Wurff P, Buijs EJ, Groen GJ. A multitest regimen of pain 
provocation tests as an aid to reduce unnecessary minimally invasive sacroiliac joint procedures. Arch Phys Med Rehabil. 2006; 87: 10-14. PubMed: https://www.ncbi.nlm.nih.gov/pubmed/16401431

18. Slipman CW, Sterenfeld EB, Chou LH, Herzog R, Vresilovic E. The predictive value of provocative sacroiliac joint stress maneuvers in the diagnosis of sacroiliac joint syndrome. Arch Phys Med Rehabil. 1998; 79: 288-292.

PubMed: https://www.ncbi.nlm.nih.gov/pubmed/9523780

19. Zou YC, Li YK, Yu CF, Yang XW, Chen RQ. A cadaveric study on sacroiliac joint injection. Int Surg. 2015; 100: 320-327.

20. Simon S. Sacroiliac joint injection and low back pain. Waldman S (ed.). Interventional Pain Management. WB Saunders. 2001; 335-339.

21. Rosenberg JM, Quint TJ, de Rosayro AM. Computerized tomographic localization of clinically guided sacroiliac joint injections. Clin J Pain. 2000; 16: 18-21.

PubMed: https://www.ncbi.nlm.nih.gov/pubmed/10741814

22. Hansen HC. Is fluoroscopy necessary for sacroiliac joint injections? Pain Physician. 2003; 6: 155-158.

PubMed: https://www.ncbi.nlm.nih.gov/pubmed/16883374

23. Sadreddini S, Noshad H, Molaeefard M, Ardalan MR, Ghojazadeh M, et al. Unguided sacroiliac injection: effect on refractory buttock pain in patients with spondyloarthropathies. Presse Med. 2009; 38: 710-716. PubMed: https://www.ncbi.nlm.nih.gov/pubmed/19217752

24. Klauser A, De Zordo $T$, Feuchtner $G$, Sögner $P$, Schirmer $M$, et al. Feasibility of ultrasound-guided sacroiliac joint injection considering sonoanatomic landmarks at two different levels in cadavers and patients. Arthritis Rheum. 2008; 59: 1618-1624.

PubMed: https://www.ncbi.nlm.nih.gov/pubmed/18975358

25. Jee H, Lee JH, Park KD, Ahn J, Park Y. Ultrasound-guided versus fluoroscopy-guided sacroiliac joint intra-articular injections in the noninflammatory sacroiliac joint dysfunction: a prospective, randomized, single-blinded study. Arch Phys Med Rehabil. 2014; 95: 330-337. PubMed: https://www.ncbi.nlm.nih.gov/pubmed/24121083

26. Vleeming A, Schuenke MD, Masi AT, Carreiro JE, Danneels L, et al. The sacroiliac joint: an overview of its anatomy, function and potential clinical implications. J Anat. 2012; 221: 537-567.

PubMed: https://www.ncbi.nlm.nih.gov/pubmed/22994881

27. Nacey NC, Patrie JT, Fox MG. Fluoroscopically Guided Sacroiliac Joint Injections: Comparison of the Effects of Intraarticular and Periarticular Injections on Immediate and Short-Term Pain Relief. AJR Am J
Roentgenol. 2016; 207: 1055-1061.

PubMed: https://www.ncbi.nlm.nih.gov/pubmed/27574965

28. Murakami E, Tanaka Y, Aizawa T, Ishizuka M, Kokubun S. Effect of periarticular and intraarticular lidocaine injections for sacroiliac joint pain: prospective comparative study. J Orthop Sci. 2007; 12: 274-280. PubMed: https://www.ncbi.nlm.nih.gov/pubmed/17530380

29. Borowsky CD, Fagen G. Sources of sacroiliac region pain: insights gained from a study comparing standard intra-articular injection with a technique combining intra- and peri-articular injection. Arch Phys Med Rehabil. 2008; 89: 2048-2056.

PubMed: https://www.ncbi.nlm.nih.gov/pubmed/18996232

30. Murata Y, Takahashi K, Yamagata M, Takahashi Y, Shimada Y, et al. Origin and pathway of sensory nerve fibers to the ventral and dorsal sides of the sacroiliac joint in rats. J Orthop Res. 2001; 19: 379-83. PubMed: https://www.ncbi.nlm.nih.gov/pubmed/11398849

31. Fortin JD, Aprill CN, Ponthieux B, Pier J. Sacroiliac joint: pain referral maps upon applying a new injection/arthrography technique. Part II: Clinical evaluation. Spine (Phila Pa 1976). 1994; 19: 1483-1489. PubMed: https://www.ncbi.nlm.nih.gov/pubmed/7939979

32. Kehl A, Corr M, Weisman M. Review: Enthesitis: New Insights Into Pathogenesis, Diagnostic Modalities, and Treatment. Arthritis Rheumatol. 2016; 68: 312-322.

PubMed: https://www.ncbi.nlm.nih.gov/pubmed/26473401

33. Braun J, Bollow M, Seyrekbasan F, Häberle HJ, Eggens $U$, et al. Computed tomography guided corticosteroid injection of the sacroiliac joint in patients with spondyloarthropathy with sacroiliitis: clinical outcome and follow up by dynamic magnetic resonance imaging. $\mathrm{J}$ Rheumatol. 1996; 23: 659-664.

PubMed: https://www.ncbi.nlm.nih.gov/pubmed/8730123

34. Kim WM, Lee HG, Jeong CW, Kim CM, Yoon MH. A randomized controlled trial of intra-articular prolotherapy versus steroid injection for sacroiliac joint pain. J Altern Complement Med. 2010; 16: 1285-1290.

PubMed: https://www.ncbi.nlm.nih.gov/pubmed/21138388

35. Slipman CW, Plastaras CT, Yang ST, et al. Outcomes of therapeutic fluoroscopically guided sacroiliac injections for definitive sacroiliac joint syndrome. Arch Phys Med Rehab. 2006; 77: 937.

36. Savran Sahin B, Aktas E, Haberal B, Harman A, Canan Y, et al. Sacroiliac pain and CT-guided steroid injection treatment: high-grade arthritis has an adverse effect on outcomes in long-term follow-up. Eur Rev Med Pharmacol Sci. 2015; 19: 2804-2811.

PubMed: https://www.ncbi.nlm.nih.gov/pubmed/26241533 